AperTO - Archivio Istituzionale Open Access dell'Università di Torino

\title{
Life Satisfaction and Cannabis Use: A Study on Young Adults
}

\section{This is the author's manuscript}

Original Citation:

Availability:

This version is available http://hdl.handle.net/2318/1610360

since 2017-06-01T18:21:41Z

Published version:

DOI:10.1007/s10902-016-9742-0

Terms of use:

Open Access

Anyone can freely access the full text of works made available as "Open Access". Works made available under a Creative Commons license can be used according to the terms and conditions of said license. Use of all other works requires consent of the right holder (author or publisher) if not exempted from copyright protection by the applicable law. 


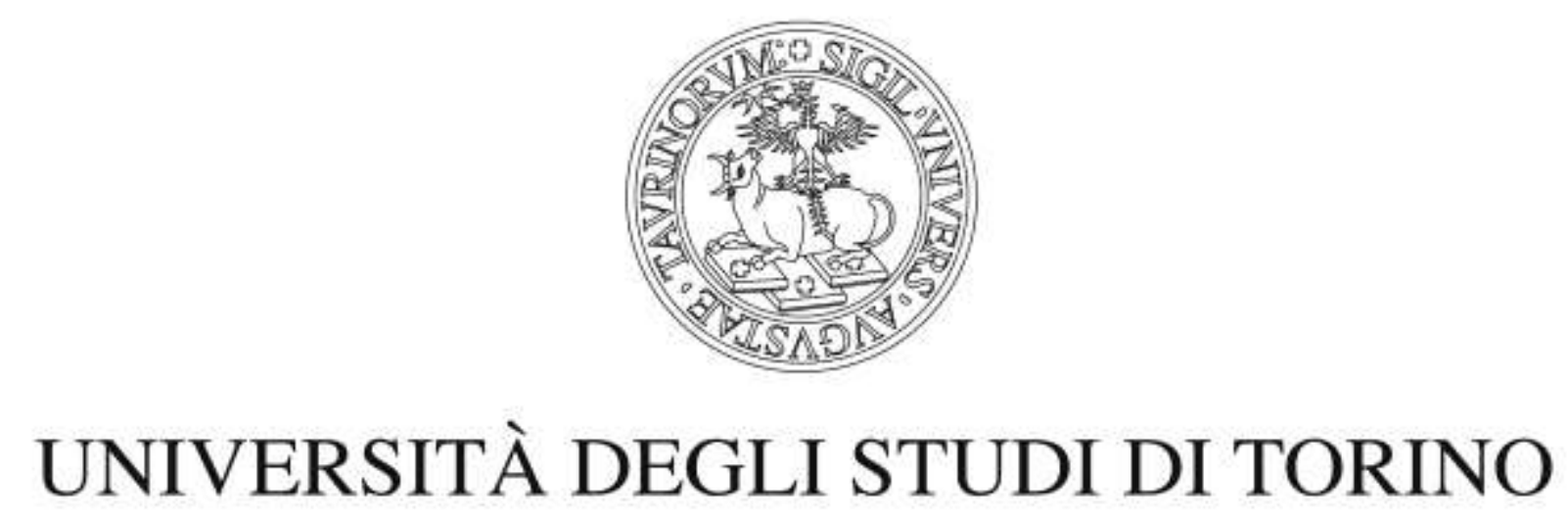

This is an author version of the contribution published on:

Questa è la versione dell'autore dell'opera:

Life Satisfaction and Cannabis Use: A Study on Young

Adults

Journal of Happiness Studies, 2016, DOI 10.1007/s10902-016-9742-0

The definitive version is available at:

La versione definitiva è disponibile alla URL:

$w w w . s p r i n g e r . c o m$ 


\section{Life satisfaction and cannabis use: A study on young adults}

\section{Stefano Tartaglia}

Anna Miglietta

Silvia Gattino

Università degli Studi di Torino, Dipartimento di Psicologia

Cannabis is the most used illicit substance in the world (WHO, 2014). The consumption of this drug is widespread among young adults and adolescents in rich nations. The general wealth of a country has been related to higher rates of cannabis use (Ter Bogt, Schmid, Nic Gabhainn, Fotiou, \& Vollebergh, 2006). Moreover, within countries, wealth and availability foster the emergence of communities of drug consumers, playing a role in the socialization of young people who may become cannabis users (Ter Bogt et al., 2013).

Cannabis use is not typical of youth with a risky health profile (Parker, Aldridge, \& Measham, 1998) but is more and more characteristic of normal young people who use it as a common recreational activity in their leisure time (Ter Bogt et al., 2013). Similar to tobacco and alcohol (Tartaglia, 2014), cannabis consumption may also occur during social interactions at parties and during nightlife. Furthermore, when young adults leave their homes, this may reduce parental control and increase substances use behaviours.

Epidemiologic research has not reported on many negative effects of the chronic use of cannabis. The adverse health and social consequences of cannabis use appear to be less severe than those of alcohol and opioid use (Degenhardt \& Hall, 2012; Hall \& Pacula, 2003). Regular cannabis users have a higher risk of experiencing psychotic symptoms and disorders with respect to non-users, but this effect is stronger for people who have a personal or family history of psychotic disorders (Hall, 
2015). Cannabis use has been related to cognitive impairment, lower educational attainment and to the use of other drugs, but all of these adverse consequences can be explained by shared risk factors and may not be the direct effects of cannabis use itself (Hall, 2015). The major adverse effect of the acute use of cannabis is the increased risk of car crashes (Gerberich, Sidney, Braun, Tekawa, Tolan, \& Quesenberry, 2003), but even this negative consequence is not as damaging as the same effect caused by alcohol intoxication. Cannabis use increases the risk of a car crash 2-3-fold, whereas the corresponding figure for alcohol users is 6-15-fold (Ramaekers, Berghaus, van Laar, \& Drummer, 2004). In a study on car crashes in France, cannabis was estimated to account for $2.5 \%$ of traffic deaths, whereas alcohol was responsible for $29 \%$ (Hartman \& Huestis, 2013). In recent years, also on the grounds of the supposedly low social and health consequences, different governments have legalised the recreational use of cannabis (e.g., Colorado in the USA, Uruguay). The negative consequences of cannabis on health and psychological states are still under debate, as cannabis use could be associated with lower scores on wellbeing indexes (i.e., life satisfaction). This research aims to investigate the relationship of life satisfaction with cannabis use in young adults, compared with the relationships of other variables. Based on previous research, we focused on personality and sociodemographic characteristics. These variables have been linked to cannabis use but have not been closely associated with life satisfaction.

Cannabis use and personality traits

Over the last thirty years, an agreement has emerged that personality can be parsimoniously described by models composed of three to seven major traits (Revelle, Condon, \& Wilt, 2011). The five-factor model of personality is a well-validated taxonomy that refers to the 'Big Five' dimensions of Extraversion, Agreeableness, Neuroticism, Conscientiousness, and Openness to Experience (Digman, 1990; Goldberg, 1993). This model is the most widely accepted; it explains individual differences in personality at a broad level of abstraction (Costa \& McCrae, 1992; 
Goldberg, 1993; McCrae \& Costa, 1999), and it shows good cross-cultural applicability (McCrae \& Costa, 1997).

Research has noted a relationship between personality traits and health (Terracciano, Löckenhoff, Zonderman, Ferrucci, \& Costa, 2008). This link may be explained by the fact that personality traits are also predictors of the consumption and abuse of different harmful substances such as alcohol, cigarettes, and drugs (Bogg \& Roberts, 2004; Flory, Lynam, Milich, Leukefeld, \& Clayton, 2002; Hampson \& Friedman, 2008; Turiano, Whiteman, Hampson, Roberts, \& Mroczek, 2012).

Concerning cannabis, three studies have found consistent results. Cannabis users exhibited lower agreeableness and conscientiousness and higher openness (Allen \& Holder, 2014; Friedberg, Vollmer, O’Donnell, \& Skosnik, 2011; Terracciano, Löckenhoff, Crum, Bienvenu, \& Costa, 2008). These studies involved very different participants. Terracciano and colleagues (2008) used a large epidemiologic sample of adults $(\mathrm{N}=1102$; mean age $=57$ years $)$. Friedberg and colleagues studied a small sample of university students and compared a group of 62 cannabis users with a group of 45 healthy drug-naïve controls. Allen and Holder (2014) used a large sample of young university students $(\mathrm{N}=570$; mean age $=19.6$ years). Another study (Flory, Lynam, Milich, Leukefeld, \& Clayton, 2002) investigated the relationship between personality and marijuana dependence. Controlling for alcohol dependence, antisocial personality disorder, and internalizing symptoms, cannabis dependence symptoms were positively related to openness and negatively related to extraversion. The partially different results of this last study may have occurred because it investigated the relationship between personality and cannabis dependence, whereas the others studied the relationship with general consumption. Although the findings concerning cannabis use are quite consistent, more research is still needed because of the lack of diversity of the samples studied. Furthermore, all of the studies cited above have been carried out in North America (three in USA and one in Canada). The Big Five traits show good cross-cultural stability; however, we still need studies in different cultural contexts to confirm these results. 
Cannabis and satisfaction with life

The results of research on the relationship between cannabis consumption and life satisfaction are conflicting. Some studies have found an association between low levels of life satisfaction and low general happiness and cannabis use (Georgiades and Boyle 2007; Gruber, Pope, Hudson, \& Yurgelun-Todd, 2003), whereas others did not find this relationship (Allen \& Holder, 2014; Barnwell, Earleywine, and Wilcox, 2006). The theoretical link between these variables is justified because cannabis consumption may be motivated by coping with personal problems and negative mood (Allen \& Holder, 2014; Fox, Towe, Stephens, Walker, \& Roffman, 2011). People may use cannabis, like other substances, with the intent to improve their low life satisfaction. A condition that positively affects the wellbeing of young adults and negatively affects substance use is involvement in a romantic relationship (Simon \& Barrett, 2010). Supportive close relationships may be a protective factor against alcohol consumption (Tartaglia, 2014). Substance abuse is a possible reaction to relational problems. This reaction is more frequent among men, whereas women are more inclined to experience depressive symptoms (Simon, 2002; Williams, 2003). This is consistent with the fact that males consume more substances than females, including cannabis (Ter Bogt et al., 2013).

The gender gap in cannabis use

In general, males have a higher consumption of cannabis compared to females and a greater tendency to abuse and develop dependence (Fergusson, Boden, \& Horwood, 2008). However, in recent decades, women have shown an increase in smoking and drinking (Holmila \& Raitasalo, 2005; Schaap et al., 2009). Rich western societies have promoted a unique world of youth culture, involving special products, styles and recreational activities such as dancing and partying that foster 
the general consumption of licit and illicit substances (Parker, Aldrige, \& Measam, 1998). At the same time, female emancipation has enabled women to frequent public spaces such as pubs, bars and clubs where the above-mentioned recreational activities take place (Kuntsche et al., 2010). Over the long term, these factors may have changed substance use habits, narrowing the gender gap in cannabis use.

\section{Current study}

Data from the Drug Policy Department of the Presidency of the Council of Ministers, published by the European Monitoring Centre for Drugs and Drug Addiction ${ }^{1}$ (EMCDDA), provide the most recent picture of drug use in Italy. An analysis of the trends in drug use shows an overall decrease in use from 2008 until now. According to the annual report of the Drug Policy Department (2014), the percentage of men using drugs was higher than the percentage of women, but a greater decrease in use was found in the male population. Cannabis was the illicit substance used most often. Regarding young adults (aged 15-24 years), Italy ranked $12^{\text {th }}$ among the 30 countries monitored by the EMCDDA in the prevalence of cannabis use in the previous month. The aim of the present study was to compare the relationship of three groups of variables with cannabis use in Italian young adults. We investigated (1) sociodemographic characteristics, (2) the Big Five personality traits, and (3) satisfaction with life. Based on the research previously cited, we expected the following results:

Concerning sociodemographic characteristics, men and participants living outside of their family home would have a higher consumption of cannabis. The participants involved in a romantic relationship would have a lower consumption.

\footnotetext{
${ }^{1}$ Data on drug use in Europe are available on the website of the European Monitoring Centre for Drugs and Drug Addiction. http://www.emcdda.europa.eu/
} 
Concerning the Big Five traits, openness would be positively associated to cannabis use, whereas agreeableness and conscientiousness would hold negative relationships with it.

Satisfaction with life would be negatively related to cannabis use.

We decided to investigate the consumption of other illicit drugs in addition to cannabis, but based on the EMCDDA data, we expected to find a very low level of use.

\section{METHOD}

\section{Participants}

The data presented here were part of those collected for a survey conducted with students from two public universities. For their master's degree thesis, three graduate students in psychology contacted other students attending courses in the Arts and Sciences schools of the two universities. The participants were contacted in classrooms and asked for their voluntary participation. The participants did not receive any incentive to respond. The majority of the students accepted, and less than $5 \%$ of the students refused to participate in the survey. The anonymity of the participants was guaranteed. Although this sampling technique was limited because it was not purely random, every effort was made to access students taking all different types of courses at the two universities. The study involved 600 participants (60.5\% male, $39.5 \%$ female). The average age of the sample was 22.20 years $(\mathrm{SD}=2.57$; range $18-33)$. A total of $57.6 \%$ of the participants lived with their parents, whereas $42.4 \%$ lived alone. Additionally, $49.1 \%$ of the participants were engaged in a romantic relationship.

\section{Measures}

We gathered the data by means of a self-report questionnaire that included four sets of variables:

- A set of drug consumption indicators. Five items investigated the frequency of consumption of different types of drug (i.e., marijuana and hashish, LSD and other psychedelic drugs, 
ecstasy, cocaine, other drugs) on a 5-point Likert-type scale ranging from 1 (never) to 5 (everyday).

- $\quad$ The Single-Item Measures of Personality (SIMP) assessed the Big Five personality traits by means of five items using a Bipolar Response Scale (Woods \& Hampson, 2005). Each item was composed of two opposing descriptions representing the poles of a Big Five factor with a nine-point scale placed between the two descriptions. Participants were asked to indicate the extent to which one pole or the other best described them. Wood and Hampson (2005) reported a mean convergence of $r=.61$ for the SIMP, with longer scales measuring Big Five traits. Moreover, its test-retest reliability was acceptable, and the criterion correlations were also comparable. This measure has been used in several investigations concerning different topics (e.g., Tartaglia \& Rollero, 2015; Want, Vickers, \& Amos, 2009; Wilde-Larsson, Sandin-Bojö, Starrin, \& Larsson, 2011).

- The Satisfaction with Life Scale (SLS) (Diener, Emmons, Larsen, Griffin, 1985) was composed of 5 items (e.g., "In most ways my life is close to my ideal"; "If I could live my life over, I would change almost nothing") that were rated on a 7-point Likert-type scale ranging from 1 (strongly disagree) to 7 (strongly agree) $($ Cronbach's alpha $=.85)$.

- A list of sociodemographic items (gender, age, living on one's own, romantic relationship status).

\section{Data analysis}

The consumption of cannabis was regressed onto different groups of variables that were entered into the analysis in three steps. In the first step, we entered sociodemographic characteristics: gender $(0=$ female; $1=$ male $)$, age, romantic relationship status $(0=$ single; $1=$ engaged $)$, and living on one's own $(0=\mathrm{No} ; 1=$ Yes $)$. In the second step, we entered the Big Five factors. In the third step, we entered satisfaction with life. Because the literature suggests that there are some associations 
between personality and gender, in a last step we tested the interaction between gender and the Big Five factors.

\section{RESULTS}

\section{Descriptive statistics}

Table 1 shows the means and standard deviations of the Big five factors and satisfaction with life.

Table 2 reports the correlations between the scales and age. Concerning personality traits, the means were all close to the central point of the scales, and the standard deviations indicated a great variety in the positions around the mean value. When thinking about their life, the participants were reasonably satisfied (the scale ranged from 1 to 7 ), and the variability was not large.

As expected, cannabis was the only drug with a large diffusion; $47.7 \%$ of the participants confirmed that they had used it at least sometimes, and $6.3 \%$ reported using it daily. The overwhelming majority of the sample had never used LSD and other psychedelic drugs (95.3\%), ecstasy (97\%), cocaine $(96 \%)$, or other drugs $(94.9 \%)$. Overall, cannabis consumption was not frequent; on a scale ranging from 1 to 5 , the mean of the sample was $1.91(\mathrm{SD}=1.21)$. We checked for the normality of the distribution of cannabis consumption. The difference from a normal distribution was acceptable $($ Skewness $=1.20 ;$ Kurtosis $=.57)$.

Hierarchical regression analysis

We calculated the variance inflation factors (VIF). The values excluded multicollinearity among independent variables. Cannabis consumption (see Table 3) was positively related to being male $(\beta=.42)$, living on one's own $(\beta=.11)$, and openness $(\beta=.11)$. In contrast, two variables were negatively related to cannabis consumption: agreeableness $(\beta=-.12)$ and satisfaction with life $(\beta=$ .13). We found an interaction between gender and conscientiousness $(\beta=-.29)$. This factor is related 
to a lower cannabis consumption only among males. The explained variance of the model was $\mathrm{R}^{2}=$ .15 .

\section{DISCUSSION}

The present study aimed to study the variables correlated to cannabis use in young adults. Cannabis was the illegal substance that was used most by the participants. The drug consumption of the sample was consistent with national data reported by the EMCDDA. Almost half of the participants occasionally used cannabis, whereas other substances were not widespread and had never been used by the overwhelming majority of the sample. The frequency of cannabis consumption was low; only a small minority of the participants used it daily. As expected, being male was related to high frequency of use. The so-called gender gap in cannabis is a common result in the literature (Fergusson, Boden, \& Horwood, 2008; Ter Bogt et al. 2013) and is consistent with the greater male consumption of substances (Ter Bogt et al. 2013) including alcohol (Johnston, O’Malley, Bachman, \& Schulenberg, 2007; Tartaglia, 2014), which is the other psychoactive substance largely used by young adults. We did not find a significant relationship between age and cannabis use. This result may be because there was a small difference in age between the participants of the present study. Participants living outside of their family home used cannabis more frequently. Living alone may imply reduced parental control for these young adults, furthering their substance use.

Concerning personality traits, the results confirmed the findings of previous North American studies (Allen \& Holder, 2014; Friedberg, Vollmer, O’Donnell, \& Skosnik, 2011; Terracciano, Löckenhoff, Crum, Bienvenu, \& Costa, 2008). Agreeableness was negatively related to the frequency of consumption of cannabis. Conscientiousness too was a protective factor, having a negative relationship with cannabis use but only for male participants. As suggested by Ball (2005), low levels of these traits may account for some of the problems commonly associated with frequent drug use, such as impulsivity (low consciousness) and problems with interpersonal relationships 
(low agreeableness). On the contrary, openness was positively related to cannabis use. Following a classical interpretation (Grossman, Goldstein, \& Eisenman, 1974), a tendency to be open to new experiences may have led individuals to try cannabis.

Satisfaction with life was negatively related to cannabis use. This result is consistent with other studies that found a relationship between low levels of life satisfaction, general happiness, and cannabis use (Georgiades and Boyle 2007; Gruber, Pope, Hudson, \& Yurgelun-Todd, 2003). A possible interpretation of this result is that cannabis use may be motivated by coping with unsatisfactory life conditions (Fox, Towe, \& Stephens, 2011). Involvement in a romantic relationship did not seem to be a protective factor; including satisfaction with life in the regression model negated the relationship of this variable. It is possible that for the participants in this study, the lack of a significant interpersonal relationship was not as serious because of their young age. This may differ for older people. However, compared to youth, older individuals generally have a lower consumption of drugs. Future studies should investigate more closely the relationship between romantic relationships and cannabis use.

This study has limitations that suggest directions for future research. First, the sampling procedure. Several studies on cannabis use have been conducted with university student samples (i.e., Allen \& Holder, 2014; Friedberg, Vollmer, O’Donnell, \& Skosnik, 2011) as did the present study. However, the students may not have been representative of the whole young adult population; therefore, further research is needed on a different sample of youth. Second, given the cross-sectional nature of the study, we express caution in interpreting the direction of the relationships between variables. Non-correlational studies may be indicated in future research to strengthen the present results. Another limitation was the amount of variance explained by the model that is quite small. Future research should try to identify other variables that explain a greater share of the variance in cannabis use. Moreover, studying drug consumption, which is an illegal behaviour, by means of a questionnaire suggests that the responses were probably affected by social desirability. In the 
present study, we had no measure for this bias. Finally, the use of single-item measures of personality may have been a possible shortcoming of the study.

Our results are consistent with the North American literature. This may suggest that the culture of cannabis is similar in European and North American countries. Epidemiological data (WHO, EMCDDA) show that, with differences in absolute values, cannabis is the most used illicit substance throughout these areas and is widespread among young adults. Cannabis use in youth seems to be somewhat globalised and in part motivated by a low satisfaction with life.

\section{REFERENCES}

Allen, J., \& Holder, M. D. (2014). Marijuana use and well-being in university students. Journal of Happiness Studies, 15(2), 301-321.

Ball, S.A. (2005). Personality traits, problems, and disorders: clinical applications to substance use disorders. Journal of Research in Personality, 39, 84-102.

Barnwell, S. S., Earleywine, M., \& Wilcox, R. (2006). Substance Abuse Treatment, Prevention, and Policy. Substance Abuse Treatment, Prevention, and Policy, 1, 1-9.

Bogg, T., \& Roberts, B. W. (2004). Conscientiousness and health-related behaviors: A metaanalysis of the leading behavioral contributors to mortality. Psychological Bulletin, 130, 887919.

Costa, P.T. \& McCrae, R. R. (1992). Four ways five factors are basic. Personality and Individual Differences, 13, 653-665.

Degenhardt, L., \& Hall, W. (2012). Extent of illicit drug use and dependence, and their contribution to the global burden of disease. The Lancet, 379, 55-70. 
Diener, E. D., Emmons, R. A., Larsen, R. J., \& Griffin, S. (1985). The satisfaction with life scale. Journal of personality assessment, 49(1), 71-75.

Digman, J. M. (1990). Personality structure: Emergence of the five-factor model. Annual Review of Psychology, 41, 417-440.

Drug Policy Department of the Presidency of the Council of Ministers (2014). National report 2013: Italy. Retrieved from http://www.emcdda.europa.eu/countries/italy

Fergusson, D. M., Boden, J. M., \& Horwood, L. J. (2008). The developmental antecedents of illicit drug use: evidence from a 25-year longitudinal study. Drug and alcohol dependence, 96(1), 165-177.

Flory, K., Lynam, D., Milich, R., Leukefeld, C., \& Clayton, R. (2002). The relations among personality, symptoms of alcohol and marijuana abuse, and symptoms of comorbid psychopathology: Results from a community sample. Experimental and Clinical Psychopharmacology, 10(4), 425.

Fox, C. L., Towe, S. L., Stephens, R. S., Walker, D. D., \& Roffman, R. A. (2011). Motives for cannabis use in high-risk adolescent users. Psychology of addictive behaviors, 25(3), 492.

Fridberg, D. J., Vollmer, J. M., O'Donnell, B. F., \& Skosnik, P. D. (2011). Cannabis users differ from non-users on measures of personality and schizotypy. Psychiatry research, 186(1), 4652.

Georgiades, K., \& Boyle, M. H. (2007). Adolescent tobacco and cannabis use: Young adult outcomes from the Ontario child health study. Journal of Child Psychology and Psychiatry, 48(7), 724-731.

Gerberich S., Sidney S., Braun B., Tekawa I., Tolan K., \& Quesenberry C. (2003). Marijuana use and injury events resulting in hospitalization. Annals of Epidemiology, 13(4), 230-237. 
Goldberg, L. R. (1993). The structure of phenotypic personality traits. American Psychologist, 48, 26-34.

Grossman, J.C., Goldstein, R., \& Eisenman, R., (1974). Undergraduate marijuana and drug use as related to openness to experience. Psychiatric Quarterly, 48, 86-92.

Gruber, A. J., Pope, H. G., Hudson, J. I., \& Yurgelun-Todd, D. (2003). Attributes of long-term heavy cannabis users: A case-control study. Psychological Medicine: A Journal of Research in Psychiatry and the Allied Sciences, 33(8), 1415-1422.

Hall, W. (2015). What has research over the past two decades revealed about the adverse health effects of recreational cannabis use? Addiction, 110(1), 19-35.

Hall, W., \& Pacula, R. L. (2003). Cannabis use and dependence: public health and public policy. Cambridge university press.

Hampson, S.E. \& Friedman, H.S. (2008). Personality and health: A life span perspective. In O. P. John, R. Robins, \& L. Pervin (Eds.). The Handbook of Personality (3rd ed.): New York: Guilford Press.

Hartman, R. L., \& Huestis, M. A. (2013). Cannabis effects on driving skills. Clinical chemistry, $59(3), 478-492$.

Holmila M., \& Raitasalo K. (2005). Gender differences in drinking: why do they still exist? Addiction, 100, 1763-1769.

Kuntsche, E., Kuntsche, S., Knibbe, R., Simons-Morton, B., Farhat, T., Hublet, A., ... \& Demetrovics, Z. (2011). Cultural and gender convergence in adolescent drunkenness: evidence from 23 European and North American countries. Archives of pediatrics \& adolescent medicine, 165(2), 152-158.

McCrae, R.R. \& Costa Jr, P.T. (1997). Personality trait structure as a human universal. American Psychologist, 52, 509-516. 
McCrae, R.R. \& Costa Jr, P.T. (1999). A five-factor theory of personality. In L. A. Pervin \& O. P. John (Eds.), Handbook of personality: Theory and research (2nd edn, pp. 139-153). New York: Guilford.

Parker H., Aldridge J., \& Measham F. (1998). Illegal Leisure: The Normalization of Adolescent Recreational Drug Use. London: Routledge; 1998.

Parker, H. J., Aldridge, J., \& Measham, F. (1998). Illegal leisure: The normalization of adolescent recreational drug use. London: Routledge.

Ramaekers, J. G., Berghaus, G., van Laar, M., \& Drummer, O. H. (2004). Dose related risk of motor vehicle crashes after cannabis use. Drug and alcohol dependence, 73(2), 109-119.

Revelle, W., Condon, D. M. \& Wilt, J. (2011). Individual differences and differential psychology: A brief history and prospect. In T. Chamorro-Premuzic, S. von Stumm \& A. Furnham (Eds.), Handbook of individual differences (pp. 3-38). Chichester: Wiley-Blackwell.

Schaap, M. M., Kunst, A. E., Leinsalu, M., Regidor, E., Espelt, A., Ekholm, O., ... \& Mackenbach, J. P. (2009). Female ever-smoking, education, emancipation and economic development in 19 European countries. Social science \& medicine, 68(7), 1271-1278.

Simon, R. W. (2002). Revisiting the Relationships among Gender, Marital Status, and Mental Health. American journal of sociology, 107(4), 1065-1096.

Simon, R.W., \& Barrett, A.E. (2010). Nonmarital romantic relationships and mental health in early adulthood: Does the association differ for women and men? Journal of Health and Social Behavior, 51, 168-182.

Tartaglia, S. (2014). Alcohol consumption among young adults in Italy: The interplay of individual and social factors. Drugs: education, prevention and policy, 21(1), 65-71.

Tartaglia, S., \& Rollero, C. (2015). The Effects of Attractiveness and Status on Personality Evaluation. Europe's Journal of Psychology, 11(4), 677-690. 
Ter Bogt T., Schmid H., Nic Gabhainn S., Fotiou A., \& Vollebergh W. (2006). Economic and cultural correlates of cannabis use among mid-adolescents in 31 countries. Addiction, 101, $241-51$.

Ter Bogt, T. F., Looze, M., Molcho, M., Godeau, E., Hublet, A., Kokkevi, A., ... \& Pickett, W. (2013). Do societal wealth, family affluence and gender account for trends in adolescent cannabis use? A 30 country cross-national study. Addiction, 109(2), 273-283.

Terracciano, A., Löckenhoff, C. E., Crum, R. M., Bienvenu, O. J., \& Costa, P. T. (2008). FiveFactor Model personality profiles of drug users. Bmc Psychiatry, 8(1), 22.

Terracciano, A., Löckenhoff, C. E., Zonderman, A. B., Ferrucci, L., \& Costa Jr, P. T. (2008). Personality predictors of longevity: activity, emotional stability, and conscientiousness. Psychosomatic medicine, 70(6), 621.

Turiano, N. A., Whiteman, S. D., Hampson, S. E., Roberts, B. W., \& Mroczek, D. K. (2012). Personality and substance use in midlife: Conscientiousness as a moderator and the effects of trait change. Journal of research in personality, 46(3), 295-305.

Williams, K. (2003). Has the future of marriage arrived? A contemporary examination of gender, marriage, and psychological well-being. Journal of health and social behavior, 44(4), 470.

Want, S. C., Vickers, K., \& Amos, J. (2009). The influence of television programs on appearance satisfaction: Making and mitigating social comparisons to "Friends". Sex Roles, 60(9-10), $642-655$.

Wilde-Larsson, B., Sandin-Bojö, A. K., Starrin, B., \& Larsson, G. (2011). Birthgiving women's feelings and perceptions of quality of intrapartal care: a nationwide Swedish cross-sectional study. Journal of clinical nursing, 20(7-8), 1168-1177.

Woods, S. A., \& Hampson, S. E. (2005). Measuring the Big Five with single items using a bipolar response scale. European Journal of Personality, 19(5), 373-390. 
World Health Organization. (2014). Cannabis. Retrieved from http://www.who.int/substance_abuse/facts/cannabis/en/ 
Life satisfaction and cannabis use: A study on young adults

\section{TABLES}

Table 1. Scales descriptive statistics: means and standard deviations.

Mean

Standard Deviation

\begin{tabular}{lcc}
\hline Big Five & & \\
Extraversion & 5.52 & 2.27 \\
Agreeableness & 4.34 & 2.21 \\
Neuroticism & 6.05 & 2.30 \\
Conscientiousness & 5.21 & 2.45 \\
Openness & 5.45 & 2.25 \\
\hline Satisfaction with Life & 4.70 & 1.19 \\
\hline
\end{tabular}


Table 2. Correlations between scales and age.

\begin{tabular}{|c|c|c|c|c|c|c|}
\hline & 1 & 2 & 3 & 4 & 5 & 6 \\
\hline \multicolumn{7}{|l|}{ 1. Extraversion } \\
\hline 2. Agreeableness & $-.130 * *$ & & & & & \\
\hline 3. Neuroticism & $-.086^{*}$ & -.052 & & & & \\
\hline 4. Conscientiousness & -.042 & $-137 * *$ & .082 & & & \\
\hline 5. Openness & .048 & $.134 * *$ & $.096 *$ & $-.184 * *$ & & \\
\hline 6. Satisfaction with Life & $.143 * *$ & -.011 & $-224 * *$ & $.088 *$ & -.020 & \\
\hline 7. Age & -.062 & .023 & .025 & -.030 & .020 & $-.084 *$ \\
\hline
\end{tabular}


Table 3. Hierarchical regression analysis on cannabis consumption.

\begin{tabular}{|c|c|c|c|c|c|}
\hline Predictors & Step 1 & Step 2 & Step 3 & Step 4 & VIF \\
\hline \multicolumn{6}{|c|}{ Socio-demographics characteristics } \\
\hline Gender (1= Male) & $.19 * *$ & $.16^{* *}$ & $.18^{* *}$ & $.42 * *$ & $5.94^{\mathrm{a}}$ \\
\hline Age & -.02 & -.03 & -.04 & -.04 & 1.02 \\
\hline Romantic relationship $(1=$ & $-.11 * *$ & $-.09 *$ & -.06 & -.06 & 1.07 \\
\hline \multicolumn{6}{|l|}{ Engaged) } \\
\hline Living on one's own (1=Yes) & $.13 * *$ & $.10^{*}$ & $.11 * *$ & $.11 * *$ & 1.04 \\
\hline \multicolumn{6}{|l|}{ Big five } \\
\hline Extraversion & & .03 & .05 & .04 & 1.07 \\
\hline Agreeableness & & $-.12 * *$ & $-.12 * *$ & $-.12 * *$ & 1.06 \\
\hline Neuroticism & & -.02 & -.05 & -.05 & 1.15 \\
\hline Conscientiousness & & $-.21 * *$ & $-.19 * *$ & -.05 & $2.70^{\mathrm{a}}$ \\
\hline Openness & & $.11 * *$ & $.11^{* *}$ & $.11^{* *}$ & 1.08 \\
\hline Satisfaction with life & & & $-.14 * *$ & $-.13 * *$ & 1.14 \\
\hline Interaction Gender X & & & & $-.29 * *$ & 6.96 \\
\hline \multicolumn{6}{|l|}{ Conscientiousness } \\
\hline $\mathrm{R}^{2}$ (corrected) & .07 & .13 & .14 & .15 & \\
\hline
\end{tabular}

${ }^{\text {a }}$ Before entering the interaction between the two variables (Step 3), the VIF values were 1.11 for Gender and 1.08 for Conscientiousness. 